\title{
Geochemical prospecting at Mesters Vig, central East Greenland and at Mârmorilik, central West Greenland
}

\author{
H. R. Cooke
}

A prospecting method used in 1975 in Greenland and reported briefly on here measures the total cold extractable amount of seven heavy metals, $\mathrm{Zn}, \mathrm{Pb}, \mathrm{Cu}, \mathrm{Co}, \mathrm{Ni}, \mathrm{Sn}$ and $\mathrm{Ag}$. The primary aim of the method is to discover and outline metal anomalies but not to determine their metal content accurately. Once an anomaly is targeted this can be done by more detailed follow-up surveys.

The two areas chosen to test the suitability of the method to Greenland conditions, were the lead-zinc mining district of Mesters Vig on the east coast and the Sorte Engel (Black Angel) mine at Mârmorilik on the west coast. The traverses run show strong anomalies over known veins (figs $37 \& 38, \mathrm{AA}^{\prime} \& \mathrm{CC}^{\prime}$; fig. $39, \mathrm{GG}^{\prime} \& \mathrm{HH}^{\prime}$ ), as well as indicating previously unknown mineralisation (fig. $38, \mathrm{BB}^{\prime}$; the western anomaly in fig. $39, \mathrm{HH}^{\prime}$ ).

\section{Sampling procedure}

The cold extraction kit fits into an aluminium box the size of a camera bag, and with reagents weighs about $1 \mathrm{~kg}$. The reagents are dithizone dye (diphenylthiocarbazone) $0.001 \%$ solution in toluene, and ammonium citrate, $5 \%$ strength. A $170 \mathrm{~mm}^{3}$ sample scoop is used. Samples of any solid can be tested, if pulverised, as well as snow or water. The sample is dropped in the ammonium citrate and dithizone solution and shaken for 15 seconds. Dissolved metal in the sample changes the colour of the standard green dithizone solution, making it light blue, indigo, purple, pink, and finally, red, with increasing amounts of metal. To measure the dissolved metal content, dithizone is added to the sample solution until the colour is brought back to the end-point blue-green. The more dithizone needed, the more dissolved metal is indicated. Due to pressure of time or lack of sufficient field solution, many of the anomalous readings in the traverses shown (as in $\mathrm{GG}^{\prime}$ and $\mathrm{HH}^{\prime}$ ) were not carried to end-point blue-green. However, even these quick and scattered samples show clear correlations with the known sulphide outcrops.

\section{Mesters Vig}

Traverse $\mathrm{AA}^{\prime}$ was taken across the main open-cut on the Blyklippen vein, to get the signature of known strong $\mathrm{Pb}-\mathrm{Zn}$ mineralisation, even though distorted by surface mining and contamination. A $40 \mathrm{~m}$ wide anomaly showed up, with a central high ( $>25 \mathrm{ml}$ ) within the vein zone of many times background.

The traverse BB' anomaly lies on the projection of the Blyklippen vein, $1.5 \mathrm{~km}$ north of its known section in the Blyklippen mine (fig. 37). A traverse along nearly the same course by Lehnert-Thiel and Vohryzka in 1967 for $\mathrm{Pb}, \mathrm{Zn}, \mathrm{Cu}$ and $\mathrm{Hg}$ showed no definite anomaly, but they got moderately high $\mathrm{Hg}$ readings $(0.5-1 \mathrm{ppm})$ on both sides of the $\mathrm{BB}^{\prime}$ anomaly. Mercury would be expected to lie beyond the other metals, because of its mobility. To 


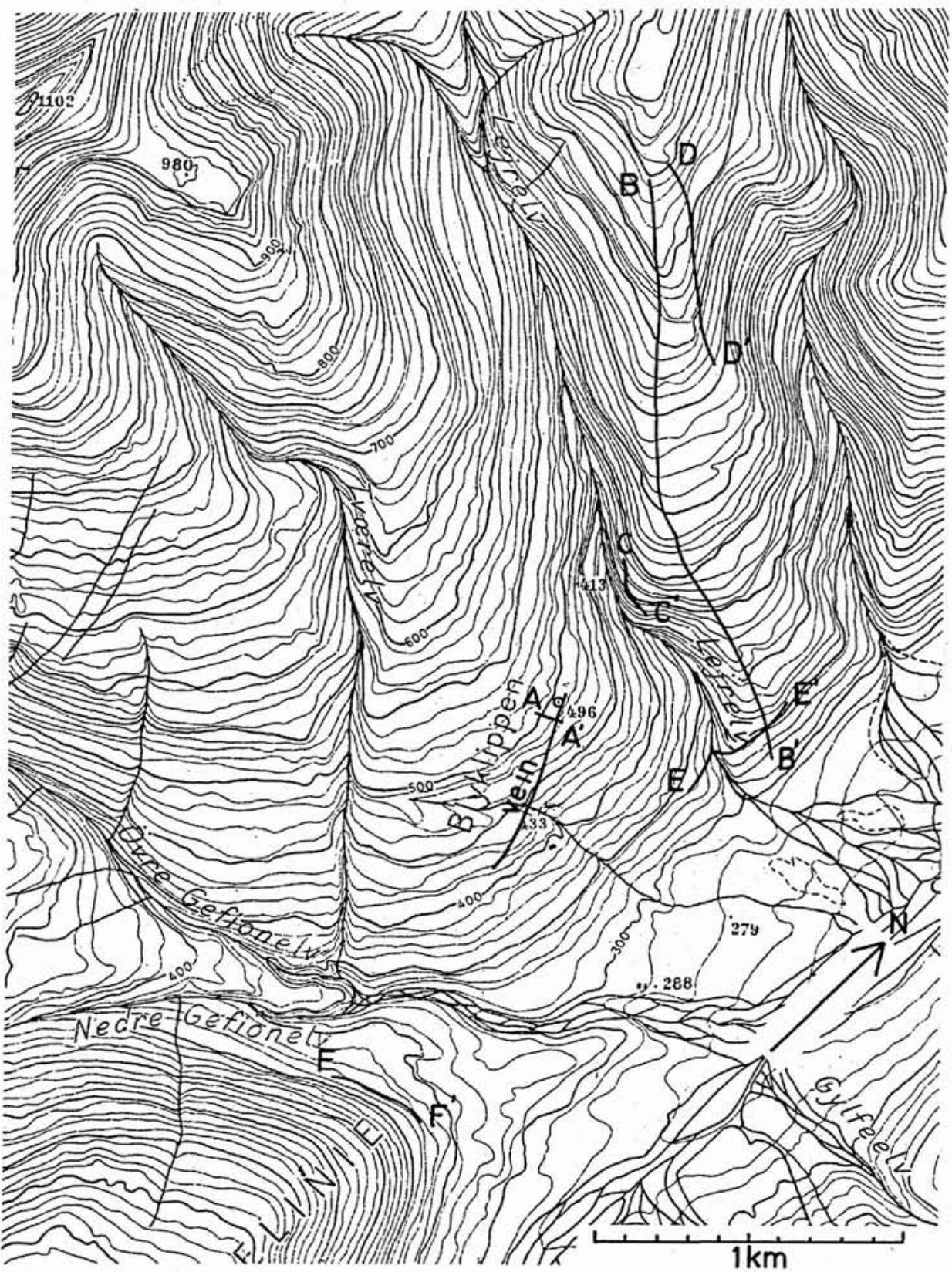

Fig. 37. Blyklippen mine area at Mesters Vig, central East Greenland, showing the location of the geochemical traverses $\mathrm{AA}^{\prime}$ to $\mathrm{FF}^{\prime}$. 


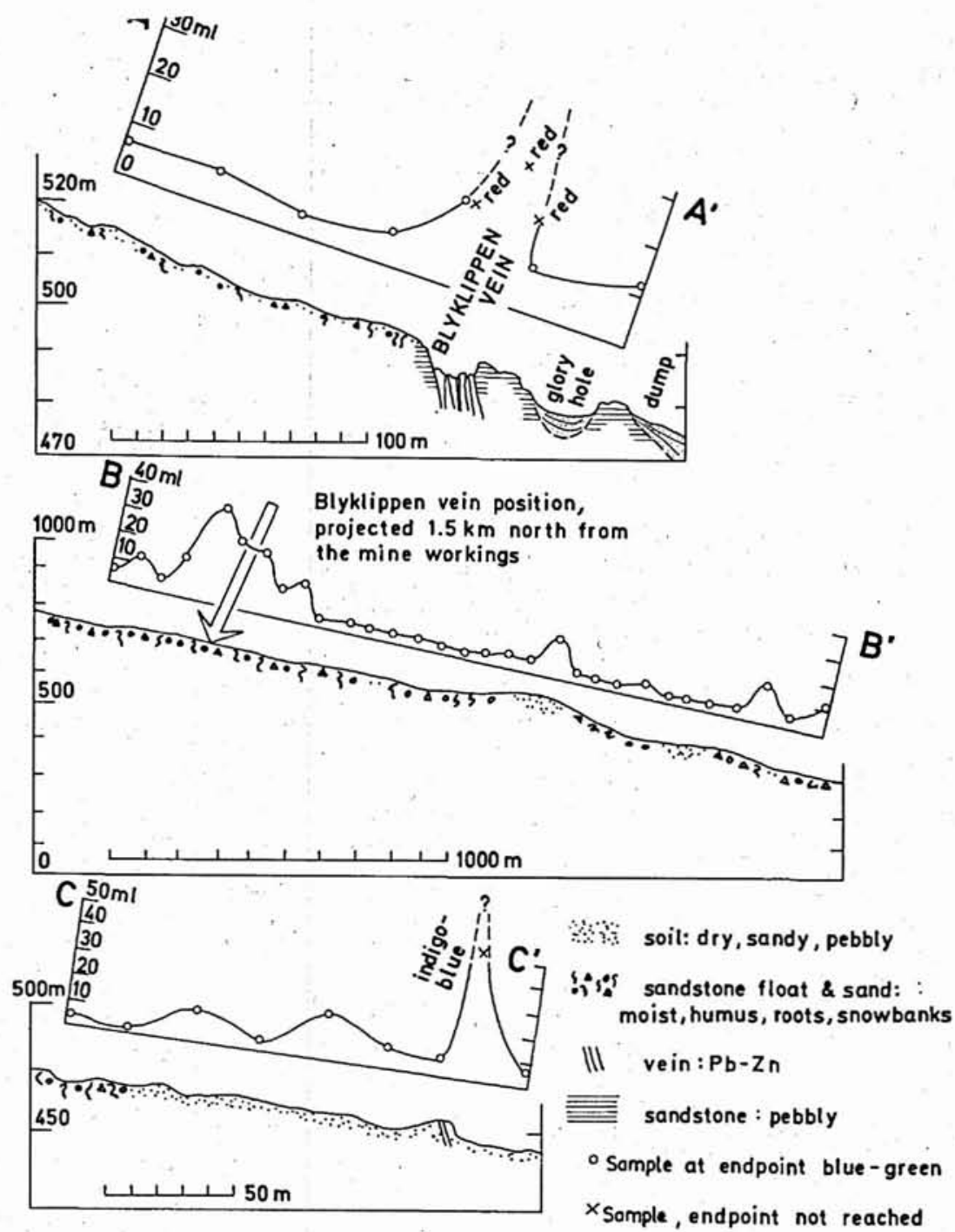

Fig. 38. Geochemical traverses in the Blyklippen mine area, Mesters Vig showing anomalies over known mineralisations $\left(\mathrm{AA}^{\prime} \& \mathrm{CC}^{\prime}\right)$ and over a hitherto unknown location (BB').

test the $\mathrm{BB}^{\prime}$ anomaly, traverse $\mathrm{DD}^{\prime}$ was run near $\mathrm{BB}^{\prime}$, also across the vein's projection. No anomaly was detected, thus indicating that the $\mathrm{BB}^{\prime}$ anomaly probably was due to a local vein rather than the Blyklippen vein. More testing is required to determine what the BB' anomaly represents.

Traverse $\mathrm{CC}^{\prime}$ picked up a vein that was mapped 20 years ago. The only anomalous reading was about a metre from the vein. This is ascribed to the traverse being run across a steep slope, where movement of metal ions is dominantly downhill, rather than laterally. 


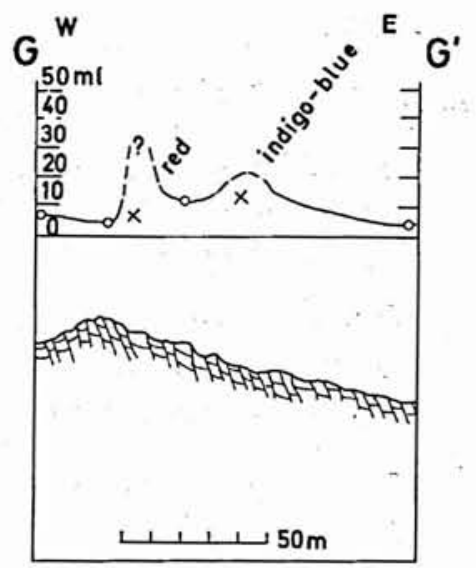

limestone / dolostone, local pelite beds

Topography sketched

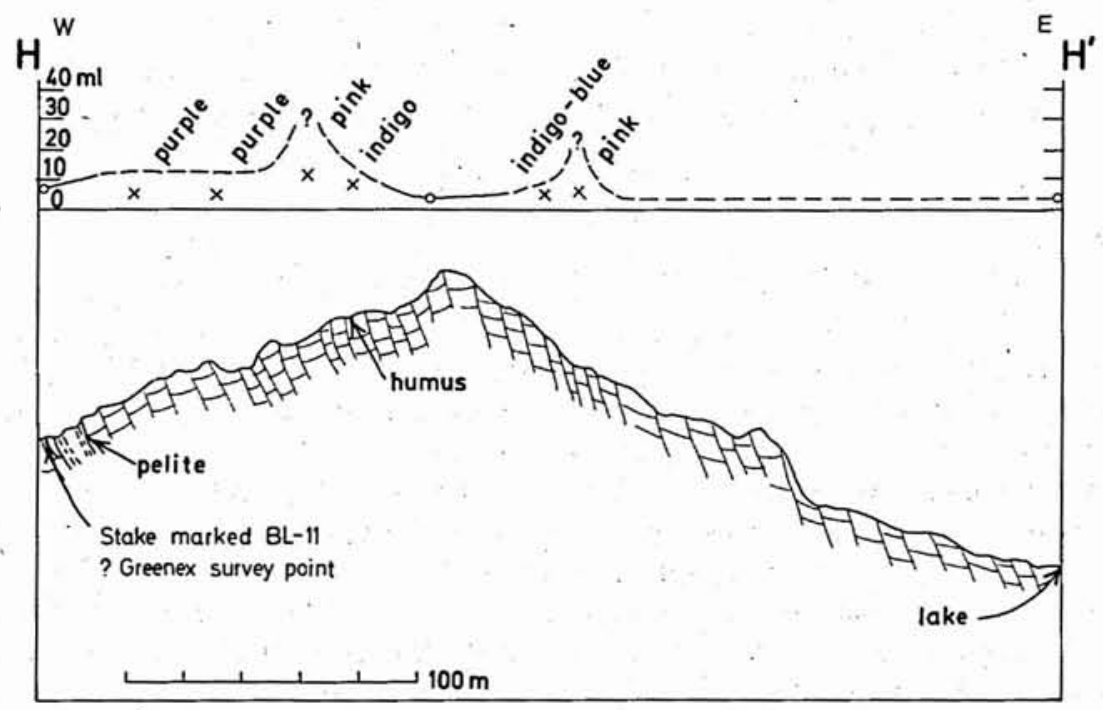

Fig. 39. Two geochemical traverses in the 'South Lakes' area, Mârmorilik, central West Greenland. Anomaly GG' and the eastern one on $\mathrm{HH}^{\prime}$ are established sites; the western one $\mathrm{HH}^{\prime}$ is a new showing.

Traverses $\mathrm{EE}^{\prime}$ and $\mathrm{FF}^{\prime}$, like $\mathrm{DD}^{\prime}$, shown only background readings and therefore are not plotted.

\section{Mârmorilik}

Traverses $\mathrm{GG}^{\prime}$ and $\mathrm{HH}^{\prime}$ were run over known Fe- $\mathrm{Zn}$ - $\mathrm{Pb}$ mineralisation of the Sorte Engel type, in the 'South Lakes' area, $4 \mathrm{~km}$ south of the Sorte Engel mine. No topographic base map of the 'South Lakes' exists, so the positions of the traverses are not shown, and the topography in the profiles is diagrammatic. 


\title{
Conclusions
}

The present survey shows that in spite of the slowness of chemical weathering and soil formation in Arctic climates, detectable quantities of cold extractable metals do accumulate in the regolith. Pulverised samples of any solid can be used and acceptable results can also be obtained on snow and water. Zinc is normally more important than the other metals accounted for both because of its mobility in surface waters and its strong reactivity with the colorimetric dye used in the geochemical method.

Although the present tests were carried out as a supplement to other field work and lack of time restricted a more thorough sampling programme the results show clear.correlations with known sulphide outcrops. Thus the method can be a useful tool in prospecting in Greenland.

\section{Reconnaissance mapping of the northern Blosseville Kyst between Kap Brewster and Kap Dalton, central East Greenland}

\author{
W. S. Watt, N. J. Soper and M. Watt
}

The northern part of the Blosseville Kyst between Kap Brewster and Kap Dalton was briefly investigated during a three week boat supported reconnaissance following an aerial interpretation of the coastal structure (Watt, 1975).

Most emphasis was laid on sorting out the relationship between the sediments at Kap Dalton and the structural relationship between the underlying and surrounding lava flows. Samples were collected for micropalaeontological studies both from the Kap Dalton sedimentary series and from a number of interbasaltic sediments (Soper \& Costa, this report). In addition a series of traverses were made through parts of the basalt succession between Kap Dalton and Steward $\emptyset$.

\section{Kap Dalton}

Wager's general interpretation of the structural setting of the Kap Dalton sediments on a down-faulted block was essentially confirmed (Wager, 1935). The block is about $5 \mathrm{~km}$ in width (fig. 40) and bounded on both flanks by major faults accompanied by crush zones up to $500 \mathrm{~m}$ in width with carbonate mineralisation along the fault planes. Along the edges of the down-faulted block the lava flows are steeply inclined $\left(\right.$ c. $\left.20-40^{\circ}\right)$ inwards against the fault plane. The down-faulted block was cut by a number of small faults after the deposition of the sediments and probably prior to the major faulting.

Soper \& Costa (this report) present palynological evidence for the age of the highest interbasaltic sediments within the down-faulted block and the age of the overlying sediments. 